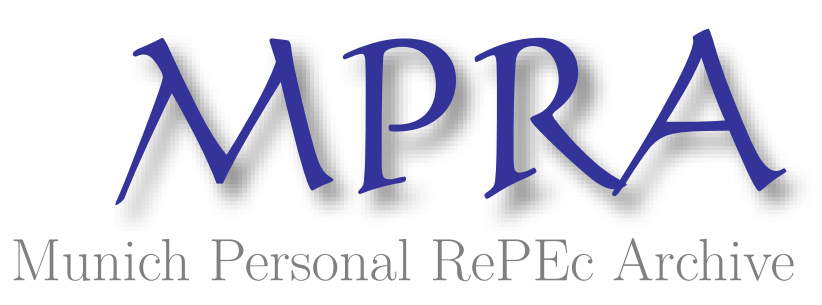

Measuring Persistence of U.S. City

Prices: New Evidence from Robust Tests

Basher, Syed Abul and Carrion-i-Silvestre, Josep Lluis

4 May 2010

Online at https://mpra.ub.uni-muenchen.de/22482/

MPRA Paper No. 22482, posted 05 May 2010 06:17 UTC 


\title{
Measuring Persistence of U.S. City Prices: New Evidence from Robust Tests*
}

\author{
Syed Abul Basher ${ }^{\dagger} \quad$ Josep Lluís Carrion-i-Silvestre ${ }^{\ddagger}$
}

May 4, 2010

Forthcoming, Empirical Economics

\begin{abstract}
This paper revisits the empirical analysis in Cecchetti, Mark and Sonora (2002) involving long-span U.S. city prices, who estimated the persistence of U.S. price differentials to be around nine years. After controlling for the structural breaks in the data, we find that U.S. city price level differentials are $\mathrm{I}(0)$ stationary processes with the median half-life of convergence ranged between 1.5 and 2.6 years, estimates that are in accordance with what should be expected from a highly integrated economy as the United States. Our results are also robust to a pairwise tests of price level convergence.
\end{abstract}

Keywords: Purchasing power parity; Price level convergence; Half-life; Multiple structural breaks; Pairwise convergence.

JEL Classification: C32, C33, E31, F41.

\footnotetext{
${ }^{*}$ The authors have benefitted from comments by two anonymous referees. J. Ll. Carrion-i-Silvestre acknowledges financial support from the Spanish Ministerio de Ciencia y Tecnología, grant ECO2008-06241/ECON. The views expressed here are those of the authors and do not reflect the official view of the Qatar Central Bank. The usual disclaimer applies.

${ }^{\dagger}$ Department of Research and Monetary Policy, Qatar Central Bank, P.O. Box 1234, Doha, Qatar. E-mail: bashers@qcb.gov.qa.

${ }^{\ddagger}$ Corresponding author: AQR-IREA Research Group, Department of Econometrics, Statistics, and Spanish Economy, University of Barcelona. Av. Diagonal, 690. 08034 Barcelona. Tel: +34 934024598; Fax: +34 93 4021821; E-mail: carrion@ub.edu.
} 
"Structural change is pervasive in economic time series relationships, and it can be quite perilous to ignore. Inferences about economic relationships can go astray, forecasts can be inaccurate, and policy recommendations can be misleading or worse."

Bruce Hansen, 2001.

\section{Introduction}

In an influential paper, Cecchetti, Mark and Sonora (2002) - hereafter CMS - using long-span series of consumer price indices for 19 U.S. cities, show that price index divergences across U.S. cities are temporary but surprisingly persistent, with a half-life of nearly nine years. To uncover explanations behind the slow rate of convergence, CMS examine the role of distance, asymmetric adjustment and non-traded goods prices. However, none of the factors were shown to provide significant explanations for the slow rate of convergence. CMS's estimated intercity Purchasing Power Parity (PPP) convergence rates are substantially more persistent than estimates of deviations from international PPP studies, which predict a half-life in the range of three to five years (see Rogoff, 1996). Recently, Nath and Sarkar (2009) - henceforth NS reexamine the CMS study by correcting for both aggregation and small-sample biases in their econometric modeling and find the half-life to be about seven years - two years shorter than the estimate of CMS.

The reason why the deviations from U.S. city PPP are substantially more persistent than deviations from cross-country PPP (as indicated by Rogoff's consensus of 3-5 years) is an intriguing question. One possible explanation is the use of long spans of data by CMS (and maintained in NS), which are more likely to be affected by structural breaks. The structural breaks can appear either because the data have been sampled across several different monetary arrangements or by the presence of shocks such as the oil price shocks. Neglect of structural breaks in the analysis can be costly and may lead to misleading results, as highlighted by Bruce Hansen in the epigraph above. The point we highlight in this paper is that lack of accounting for structural breaks in the computation of the half-life is the reason behind the slow rate of convergence documented by CMS and NS, among other authors.

The paper is organized as follows. Section 2 provides a brief discussion of the various PPP concepts under structural breaks, the estimation methodology and the database used in this paper. Section 3 presents the empirical results when the U.S. price level is used as the benchmark and when the analysis is performed in a pairwise basis. Section 4 concludes the paper. 


\section{Dealing with PPP and Structural Breaks}

Although the issue of structural breaks has received increasing attention in the analysis of PPP in recent years (both in time series and panel data), there is one important issue that is often overlooked, i.e., which notion of PPP to test when there are structural breaks in the data. The work of Cassel (1918), Balassa (1964) and Samuelson (1964) defined two well-accepted and popular PPP definitions, which have been profusely studied in the economic literature. One way to find out whether PPP hypothesis holds is by assessing the order of integration of the real exchange rates. Empirically, the distinction between Cassel and Balassa-Samuelson definitions can be established depending on the deterministic component that is used to assess the stochastic properties of real exchange rates. Thus, when the deterministic component which is used in the computation of the unit root and stationarity tests - is given by a constant term we are dealing with Cassel's (1918) definition of the PPP. By contrast, Balassa (1964) and Samuelson (1964) devised a second concept of PPP when noticing that divergent international productivity leads to permanent deviations from the Cassel's PPP definition. This feature is captured through the specification of a long-run trend around which the real exchange rates would show I(0) stationary fluctuations, which defines the so-called "Trend PPP" (TPPP). However, these notions of PPP are not valid when structural breaks are present in the data, since they assume stable deterministic components. Therefore, compatible definitions of PPP must be used for the proper fulfilment of the classical PPP hypothesis that accounts for structural breaks, giving rise to the following generalizations:

1. Quasi Purchasing Power Parity (QPPP): Testing whether the real exchange rates are $\mathrm{I}(0)$ stationary around a changing level.

2. Trend Qualified Purchasing Power Parity (TQPPP): Testing whether the real exchange rates are $\mathrm{I}(0)$ stationary around a deterministic component given by a linear time trend with level and/or slope shifts.

As can be seen, QPPP (TQPPP) is the time-varying analogue of Cassel (Balassa-Samuelson) concept of PPP that can handle the presence of structural break(s). ${ }^{1}$ Nevertheless, evidence in favor of QPPP or TQPPP does not imply that PPP as defined in Cassel or Balassa-Samuelson is fulfilled, since in these cases PPP requires reversion towards a constant mean or a constant trend

\footnotetext{
${ }^{1}$ Econometrically, QPPP is equivalent to Perron's (1989) "crash" model (model A), while TQPPP is equivalent to a combination of the "crash" and "changing growth" (model C) in Perron (1989).
} 
in the long-run, respectively. Therefore, in the presence of structural breaks, QPPP or TQPPP is necessary but not sufficient condition for the classical PPP definitions to hold. Thus, when we have found evidence in favor of QPPP or TQPPP, further investigations should be conducted to conclude that the PPP hypothesis is satisfied according to the classical definitions in Cassel or Balassa-Samuelson. To be specific, we require to impose the so-called parity restrictions on the coefficients of the first and last regimes so that the coefficients of these regimes are of the same sign and magnitude. Note that after imposing the parity restrictions the deterministic component does not change in the long-run.

Basher and Carrion-i-Silvestre (2009) - hereafter BCiS - proposed an econometric framework that encompasses the presence of multiple structural breaks while simultaneously testing for different concepts of PPP that have been described above. Their proposal is illustrated using annual consumer price level (CPI) covering the period 1918 to $2005(T=88)$ for $N=17$ U.S. cities. ${ }^{2}$ The analysis of (individual and panel) stationarity and discussion of price level convergence (either QPPP or TQPPP definitions) among the U.S. cities are presented in detail in $\mathrm{BCiS}$, although the overall conclusion is that price differentials can be considered as $\mathrm{I}(0)$ stationary processes once both structural breaks and cross-section dependence are taken into account. We take their results as starting point and proceed to compute the speed of price level convergence across U.S. cities using their data set.

\section{Estimation Results}

\subsection{Half-life Estimates: U.S. Price Level as the Benchmark}

Following CMS we have estimated the persistence of price level adjustment using the popular half-life (HL) measure - i.e., the time it takes for $50 \%$ of a shock to the price level to dissipate. As is well known that least squares (LS) estimators of the $\operatorname{AR}(p)$ model with time trend generate substantial biases, we have employed the approximate median unbiased (MU) estimators of Andrews and Chen (1994), which provides a bias-correction for the LS estimator. To implement the MU estimator, we have estimated an $\operatorname{AR}(p)$ model for each time series using the estimated number and position of the structural breaks in BCiS. For each time series, we have selected

\footnotetext{
${ }^{2}$ The cities are: Atlanta, Boston, Chicago, Cincinnati, Cleveland, Detroit, Houston, Kansas City, Los Angeles, Minneapolis, New York, Philadelphia, Pittsburgh, Portland, San Francisco, Seattle, and St. Louis. Note that, the original CMS's sample consists of 19 cities including Baltimore and Washington DC. However, since 1996, the Bureau of Labor Statistics no longer maintains separate data for these two cities. As a result, these cities are excluded from the analysis. All data come from the Bureau of Labor Statistics's webpage (www.bls.gov).
} 
between the QPPP and TQPPP sort of models using the Bayesian information criterion (BIC). ${ }^{3}$ Thus, the results presented in Table 1 point to the best model (either QPPP or TQPPP) for each series. These results are further categorized as unrestricted (when PPP is not imposed, second column in Table 1) and restricted (when PPP constraint is imposed on the TQPPP specification, fourth column in Table 1) models - note that estimated break dates are also reported.

The estimated HL and the corresponding break points reported in Table 1. As can be seen, the break points are estimated around the years of the 1929 Great Depression, World War $\mathrm{II}^{4}$, the collapse of the Bretton Woods system (1971), the oil shocks (1973, 1979), the great moderation (mid-eighties), and the early 1990's economic crisis. These are the major events affecting the prices in the U.S. and, hence, the prices of U.S. cities, although they have affected the city price differentials in a heterogeneous way - i.e., note that the break points are not present in all series. ${ }^{5}$ Finally, it should be highlighted that some of the estimated break points are closely in line with the ones detected in Sonora (2009) - he performs the analysis allowing for a maximum of two structural breaks, which are placed in the Depression era or in the 1970s.

The results concerning HL are very encouraging, with point estimates between one and three years for majority of the cities. More importantly, the average and median speed of convergence are not only faster than the estimates obtained by CMS and NS, they are also well below than Rogoff's (1996) consensus estimates of $3-5$ years. In a simpler setup after allowing for breaks, Sonora (2009) also obtained faster convergence of city relative prices, while Chen and Devereux (2003) report a half-life of nearly five years, but did not consider structural breaks in their analysis. However, the estimates reported in Sonora (2009) and Chen and Devereux (2003) are not correct unless the model is an $\mathrm{AR}(1)$ process, so their conclusions have to be taken with caution. Our results are not upset when the PPP restriction is imposed in the computation of HLs. The estimated HLs are within the neighborhood of consensus range: the mean is 3.859 and the median is 2.614 years. This is reassuring for the different approaches used in the analysis, as both restricted and unrestricted models show evidence of faster reversion to price level parity

\footnotetext{
${ }^{3}$ Results remain unaffected if we use the Akaike information criterion. A companion appendix containing unreported results is available on request from the corresponding author.

${ }^{4}$ The War Production Board and other agencies managed the production and distribution of key fuels and materials. The Office of Price Administration controlled pricing, and basic commodities were rationed. Rationing ended in 1947.

${ }^{5}$ There are other possible causes for the rest of estimated breaks - for instance, in 1952-1953, crude oil and energy prices increased due to the Iranian nationalization of oil companies, and strikes by oil, coal, and steel workers in the U.S., see Hamilton (1983).
} 
in general.

\subsection{Half-life Estimates: Pairwise Analysis}

The preceding analysis assumes that U.S. city price levels converge towards the aggregate U.S. price level. The main drawback of this approach is that results can be sensitive to the choice of the benchmark and, as a result, can lead to misleading conclusions. For example, it could be that the price deviations between a pair of cities is $\mathrm{I}(0)$ stationary, but their deviations computed separately against the aggregate U.S. price level could be non-stationary. The fact that price levels converge between this pair would be lost by just focusing on the aggregate U.S. price level. To overcome this limitation, we follow Pesaran et al. (2009) in order to compute the pairwise estimates of the price convergence rates. Given $N$ time series of prices, the pairwise tests focus on all possible $N(N-1) / 2$ price deviation pairs between the time series in the panel, and can consistently estimate the proportion of pairs that do not converge.

We have computed median unbiased half-life estimates for all $N(N-1) / 2=136$ pairs of price differentials. In order to get a complete picture, we have summarized in Table 2 the percentage of HLs that are below, within and above the 3-5 years consensus. Note that the vast majority of HLs are below or within the consensus for the three different situations that we consider. Further, Table 2 also reports the mean and median of the HL estimates for the combination of the QPPP/TQPPP specifications - detailed results for the QPPP and TQPPP specifications for each pair of time series are available upon request. As can be seen, the median half-life estimate shows a rapid adjustment to PPP than Rogoff's (1996) consensus range of 3-5 years, whereas the mean is close to five years. Similar results are also found when using the QPPP and TQPPP specifications.

\section{Conclusions}

We have discussed how structural breaks introduce conceptual and econometric difficulties that complicate the interpretation of PPP, and thereby impacting the computations of the half-life of PPP deviations. The crux of the issue is that unattended structural breaks introduce an upward bias in the autoregressive coefficients of the AR models that have been adjusted to price level differentials. This in turn implies upward bias in the persistence measure of the PPP deviations, falsely leading us to conclude that shocks affecting price differentials are highly 
persistent. Once the structural breaks are accommodated in the analysis, we obtain a median half-life of convergence ranged between 1.5 and 2.6 years, much faster than those documented in previous studies. As a check of robustness, we have extended the analysis to conduct pairwise tests of price level convergence. The finding is broadly consistent with those obtained from the aggregate U.S. price level. Consequently, our analysis raises a warning flag about common practice of econometric modeling related to the PPP puzzle.

\section{References}

Andrews, D.W.K. and Chen, H.Y. (1994). Approximately median-unbiased estimation of autoregressive models, Journal of Business and Economic Statistics 12, 187-204.

Balassa, B. (1964). The purchasing parity power doctrine: A reappraisal, Journal of Political Economy 72, 584-596.

Basher, S.A. and Carrion-i-Silvestre, J.L. (2009). Price level convergence, purchasing power parity and multiple structural breaks in panel data analysis: An application to U.S. cities, Journal of Time Series Econometrics 1(1), Article 3.

Cassel, G. (1918). Abnormal deviation in international exchanges, Economic Journal 28, 413-415.

Cecchetti, S.G., Mark, N.C. and Sonora, R.J. (2002). Price index convergence among United States cities, International Economic Review 43, 1081-1099.

Chen, L.L. and Devereux, J. (2003). What can US city price data tell us about purchasing power parity? Journal of International Money and Finance 22, 213-222.

Hamilton, J. D. (1983). Oil and Macroeconomy since World War II, Journal of Political Economy 91, 2, 228-248.

Hansen, B.E. (2001). The new econometrics of structural change: Dating breaks in US labor productivity, Journal of Economic Perspective 15, 117-128.

Nath, H.K. and Sarkar, J. (2009). Unbiased estimation of the half-life to price index convergence among US cities, Journal of Money, Credit and Banking 41, 1041-1046.

Perron, P. (1989). The great crash, the oil price shock, and the unit root hypothesis, Econometrica 57, 1361-1401.

Pesaran, M.H., Smith, R.P., Yamagata, T. and Hvozdyk L. (2009). Pairwise tests of purchasing power parity, Econometric Reviews 28, 495-521.

Rogoff, K. (1996). The purchasing power parity, Journal of Economic Literature 34, 647-668.

Samuelson, P.A. (1964). Theoretical notes on trade problems, Review of Economics and Statistics $46,145-154$.

Sonora, R. (2009). City relative price convergence in the USA with structural break(s), Applied Economics Letters 16, 939-944. 
Table 1: Half-life estimates of price level convergence towards U.S. CPI: QPPP and TQPPP hypotheses specification

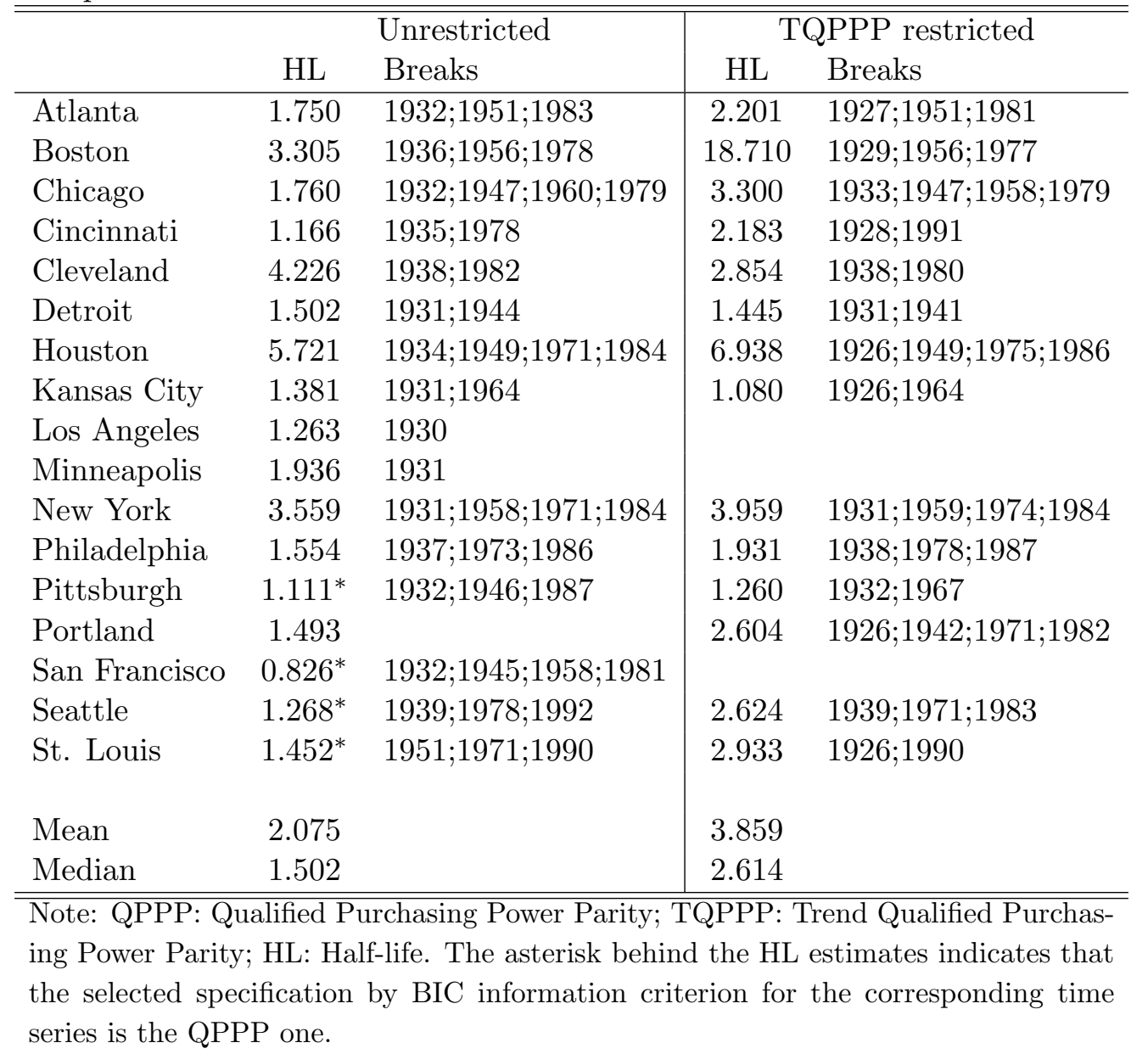

Table 2: Proportion of pairwise half-life that are below, within and above the Rogoff's (1996) $3-5$ years consensus view

\begin{tabular}{lccc}
\hline \hline & $H L<3$ & $3 \leq H L \leq 5$ & $5<H L$ \\
\hline QPPP & $67.6 \%$ & $15.4 \%$ & $16.9 \%$ \\
TQPPP & $79.7 \%$ & $6.8 \%$ & $13.5 \%$ \\
Mixed & $82.4 \%$ & $10.3 \%$ & $7.4 \%$ \\
& & \multicolumn{2}{c}{. } \\
\cline { 2 - 2 } & Mean & 5.419 \\
\multicolumn{4}{c}{1.766} \\
\hline Note: & QPPP: Qualified Purchasing Power \\
Parity; TQPPP: Trend Qualified Purchasing \\
Power Parity. HL: Half-life.
\end{tabular}

